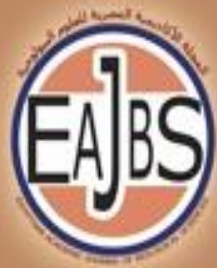

EGYPTIAN ACADEMIC JOURNAL OF
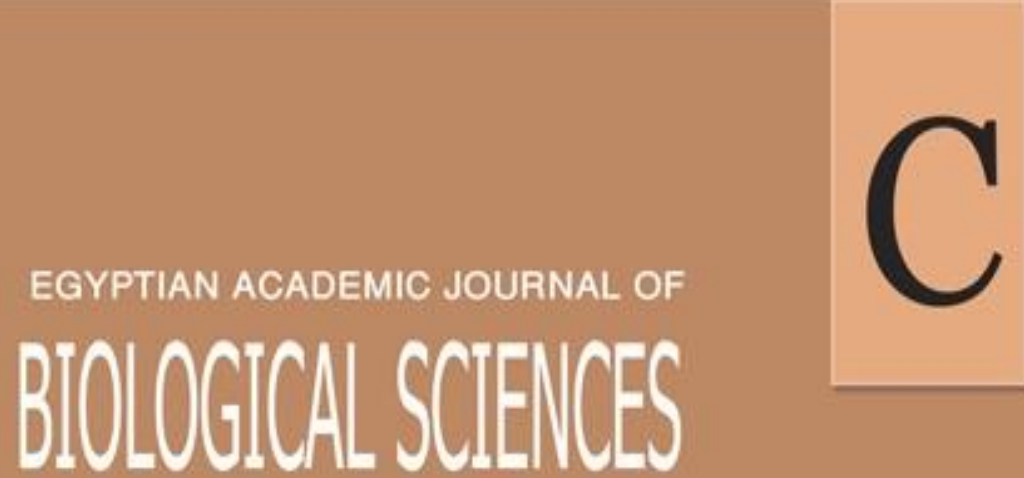

PHYSIOLOGY \& MOLECULARBIOLOGY
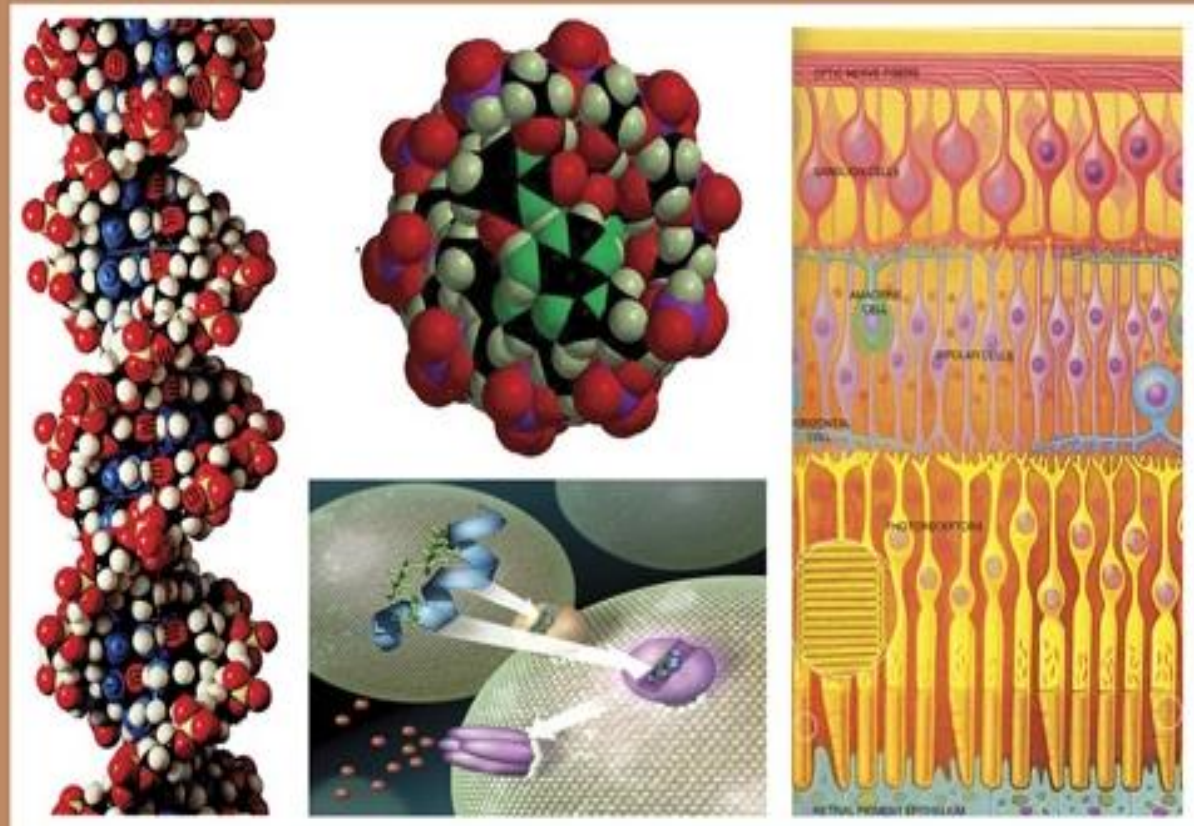

ISSN

2090-0767

WWW.EAJBS.EG.NET

Vol. 13 No. 2 (2021)

Citation: Egypt.Acad.J.Biolog.Sci. ( C.Physiology and Molecular biology) Vol. 13(2) pp27-35 (2021) 
Egypt. Acad. J. Biolog. Sci., 13(2):27-35 (2021)

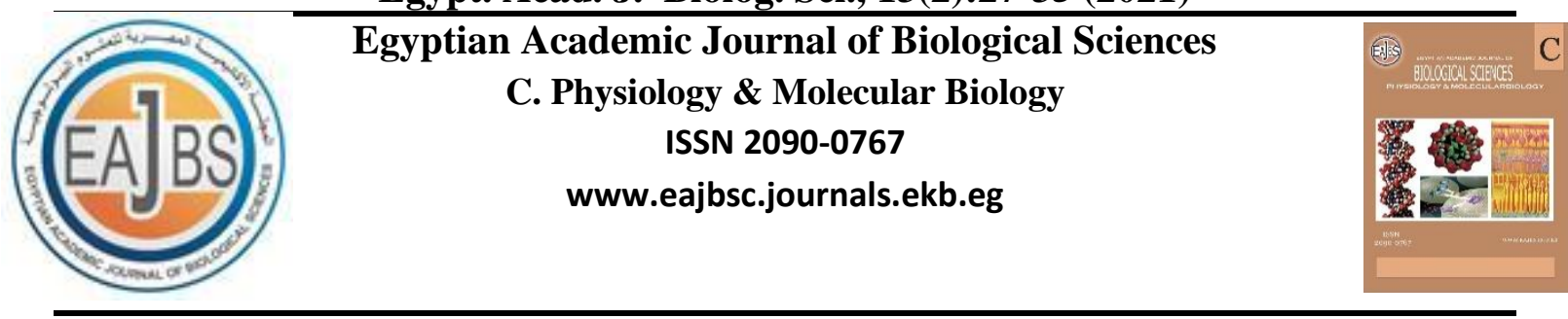

\title{
Comparative Study of Some Parameters in The Diagnosis of Diabetic Nephropathy
}

\author{
Tiboura Ghania ${ }^{1}$, Chikr Khadidja ${ }^{2}$, Megherbi Zouaouia ${ }^{2}$ and Meziani Samira ${ }^{3}$ \\ 1- Laboratory of Nutrition, Pathology, Agro Biotechnology and Health, Department of \\ Biology, Faculty of Life Sciences, Djilali Liabes. 12 Rue Oulhaci Mokhtar. \\ University of Sidi-Bel-Abbes, Algeria. \\ 2- Department of Biology, Faculty of Life Sciences, Djilali Liabes. 12 Rue Oulhaci \\ Mokhtar. University of Sidi-Bel-Abbes, Algeria. \\ 3-Laboratory of Biotoxicology, Department of Biology, Faculty of Life Sciences, Djilali \\ Liabes. 12 Rue Oulhaci Mokhtar. University of Sidi-Bel-Abbes, Algeria. \\ *E. Mail : ghania_biologie@yahoo.fr
}

\section{ARTICLE INFO} Article History

Received:28/6/2021

Accepted:17/8/2021

Keywords:

Diabetes, Diabetic nephropathy, Microalbuminuria, creatinin, stage renal disease.

\section{INTRODUCTION}

\section{ABSTRACT}

Objective: Our objective is to conduct a comparative retrospective epidemiological study of some specific biochemical and physiological parameters in the diagnosis of diabetic nephropathy. Materials and Methods: 217 diabetic patients (DT1, DT2) aged 15 to 89 years were recruited, they were classified into three groups according to the degree of renal complications. The following blood parameters were studied: glucose, HbA1C, urea, creatinine, creatinine clearance, microalbuminuria, total cholesterol, HDL, LDL, and potassium ions, sodium, chlorine.

Results: $51 \%$ of our diabetic patients are men, type 2 diabetes is more common than type 1 with a percentage of $82 \%$ (177 cases) against $18 \%$ (40 cases). The age group most affected is that of 65-89 years $(47 \%)$. the male sex was most affected by chronic kidney failure $(61 \%)$. $59 \%$ of diabetes cases are affected by hypertension. An unbalanced blood glucose was recorded in all of our patients included in this study. Urea, creatinine, creatinine clearance, microalbuminuria are biochemical markers and parameters for estimating renal function. The rate of urea, creatinine, microalbuminuria is very high in patients with diabetic nephropathy including chronic renal failure compared to other groups, which lead to the decrease in creatinine clearance [urea: $4.15 \pm 14.66$, creatinine: $71.77 \pm 43.46$, creat cl: $10.75 \pm 7.98$, microalbuminuria: $3507.11 \pm 4080.39]$.

Conclusion: Diabetic nephropathy is one of the complications of diabetes and requires optimal management to slow the progression of renal disease.

Diabetes mellitus is a major public health problem, it is defined by the chronic rise in the concentration of glucose in the blood (hyperglycemia) and groups together in a true syndrome several diseases of different pathogenesis (a disorder of secretion and/or the action of the insulin) (Blickle et al., 1999). 
Diabetes, whether type 1 or 2 , represents a significant burden in public health mainly because of the long-term complications that it promotes (Fontbonne, 2014), among these complications diabetic nephropathy (DN) is a frequent and dangerous diabetes complication. Almost half of the diabetic patients suffer from chronic kidney disease, which places them at a very high risk of cardiovascular disease (Valérie et Philippe, 2010).

Diabetic nephropathy is a gradual increase in proteinuria in long-term diabetic, followed by a renal dysfunction that can ultimately lead to end-stage renal failure (Philip et al., 2013). DN is a pathology whose incidence is steadily increasing in industrialized countries (Weekers et Krzesinski, 2005), it became the leading cause of chronic dialysis in 1998. Since then, the incidence of this disease has increased, with only one recent plateau. However, diabetic nephropathy continues to account for a large proportion of all chronic kidney disease (CKD) cases and remains by far the most common underlying cause of chronic dialysis in all kidney diseases (Masakazu, 2015).

Our work aims to make a comparative retrospective epidemiological study of some specific biochemical and physiological parameters for the diagnosis of diabetic nephropathy. For this, in our survey, we chose a population of patients who suffer from diabetes (T1D, T2D) or diabetic nephropathy and who are supported by two hospital services in Sidi Bel Abbes city. The collection of sociodemographic and clinical data of the patients recruited in this study was carried out from medical records, and also on the basis of a previously established questionnaire.

\section{MATERIALS AND METHODS}

A comparative retrospective epidemiological survey was carried out at the El Hassani AEK University Hospital Center (CHU) of Sidi Bel Abbes city at the level of two services: Department of
Endocrinology and Diabetology and Department of Nephrology and Hemodialysis. Our study was carried on a sample of people with type 1 and type 2 diabetes, suffering from Diabetic nephropathy (DN). We targeted two groups of patients: those who had DN, and those who had not yet developed this type of complication. Patients suffering from a type of diabetes other than type 1 and type 2 diabetes were excluded from this survey (Gestationnel. D, inaugural.D....). This study was carried out on a sample of 217 patients aged between 15 and 89 years. The data are recorded from clinical files and medical records (the archives during the period of 2017-2019). In this study, we tried to extract as much data as possible about patients with T1D, T2D, and ND from their archived files: Administrative data and sociodemographic aspect (surname, first name, age, sex and origin of patients, weight and height), history of the disease (diagnosis of diabetes, type of diabetes, progression to nephropathy, other complication of the disease (hypertension, diabetic retinopathy, etc.), Treatments undertaken (Antihypertensives, Antidiabetics ...), family history and the biochemical analyzes carried out.

\section{Ethical Approval:}

The Medical Committee of Sidibel-Abbes University Hospital approved the study. Informed consent was obtained from each participant after a full explanation of the study.

\section{Statistical Analysis:}

Statistical analysis was performed using the Statistical Package for the Social Sciences (SPSS®) version 20.0 (IBM Corporation, Chicago, IL., 2011). The results were expressed as mean $\pm \mathrm{SD}$. Groups' means were compared using the student t-test. A p-value of less than 0.05 was considered statistically significant.

\section{RESULTS AND DISCUSSION}

In our population, we recorded 217 cases of diabetes (T1D and T2D); $51 \%$ (111) males and 49\% (106) females with a 
sex ratio $\mathrm{M} / \mathrm{F}$ of 1.05. Men are more affected than women, our results conform to the national study of (Zaoui et al, 2007) and the international study of (Odile et $a l$, 2008) which found these rates respectively: $20.4 \%, 4.7 \%$ in men and $10.7 \%, 3.3 \%$ in women. T2D is more common than T1D with a percentage of $82 \%$ (177 cases) against $18 \%$ (40 cases) of T1D. This distribution, which shows a clear predominance of T2DM, is well in line with the proportions usually observed in the general population which places the prevalence rate of $\mathrm{T} 2 \mathrm{D}$ at over $90 \%$ of all diabetics in the world (FID, 2018; OMS, 2018). The age of our studied population is between 15 and 89 years old, and we have divided our patients into 3 age groups, the age group most affected by diabetes mellitus is $65-89$ years (47\%), followed by 40-64 years (36\%). The 15-39 age group represents $17 \%$. T1D $(78 \%)$ is predominant in the young population, unlike T2D which affects the elderly $(55 \%)$ and which increases with age, but this predominance of T1D and the reasons for this increase are not yet known with certainty but changes in environmental risk factors, events occurring in the early stages of pregnancy, early life feeding and viral infections may play a role (FID, 2013).

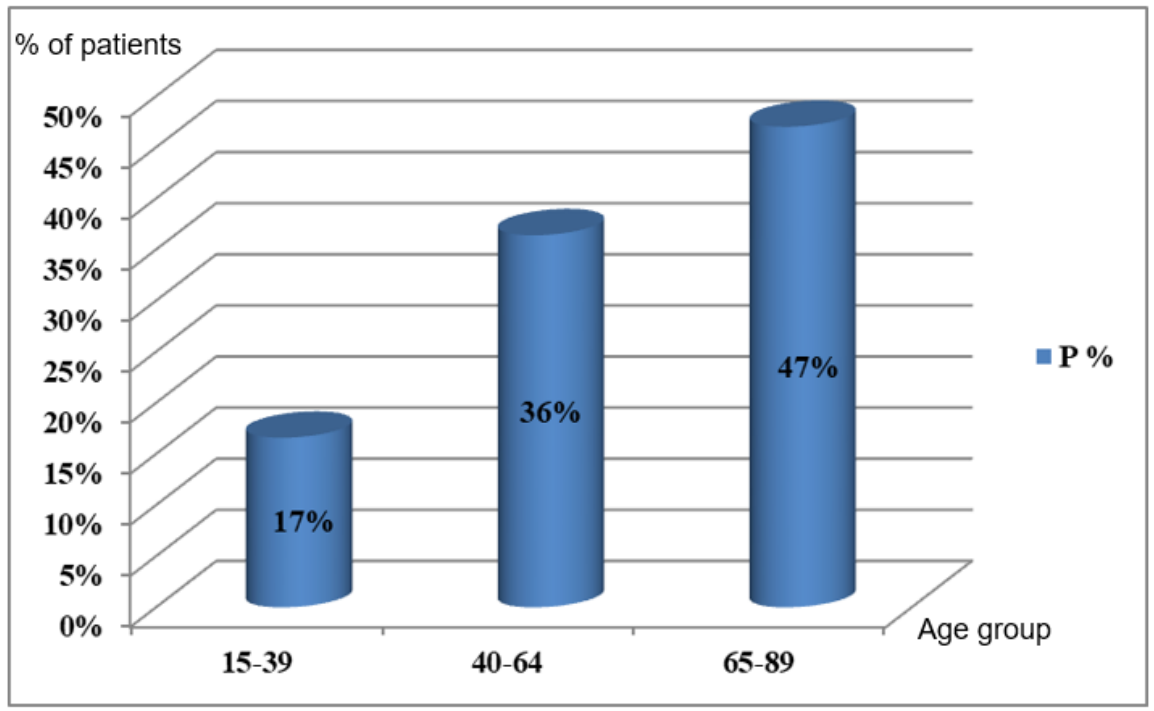

Fig. 1: Distribution of patients by age group

Our results are therefore confirmed by the results of (Malek et al, 2001; Bouattar et $a l$, 2009) which show that the prevalence of T2DM increases with age.

Diabetes is currently the leading cause of end-stage renal disease in Western countries. Diabetic nephropathy affects $25-40 \%$ of people with type 1 or types 2 diabetes. People with diabetes, especially those with kidney complications, also face an increased risk of death from cardiovascular disease. (MCV). Therefore, the early identification of high-risk individuals and the application of preventive treatments are of extreme importance (McIsaac and Jerums, 2003)
Regarding the distribution of patients by degree of complications and sex; our results showed very similar percentages for females and males in both the DWRC and EDNP groups, unlike the CRF group where it was revealed that the male sex is more affected by chronic kidney failure (61\%) than the female sex (39\%). The distribution of our patients by degree of complication is consistent with other studies where researchers have shown that the frequency of diabetic nephropathy and chronic renal failure is higher in men than in women (Djrolo et $a l$, 2001; Perucca et al, 2008). 


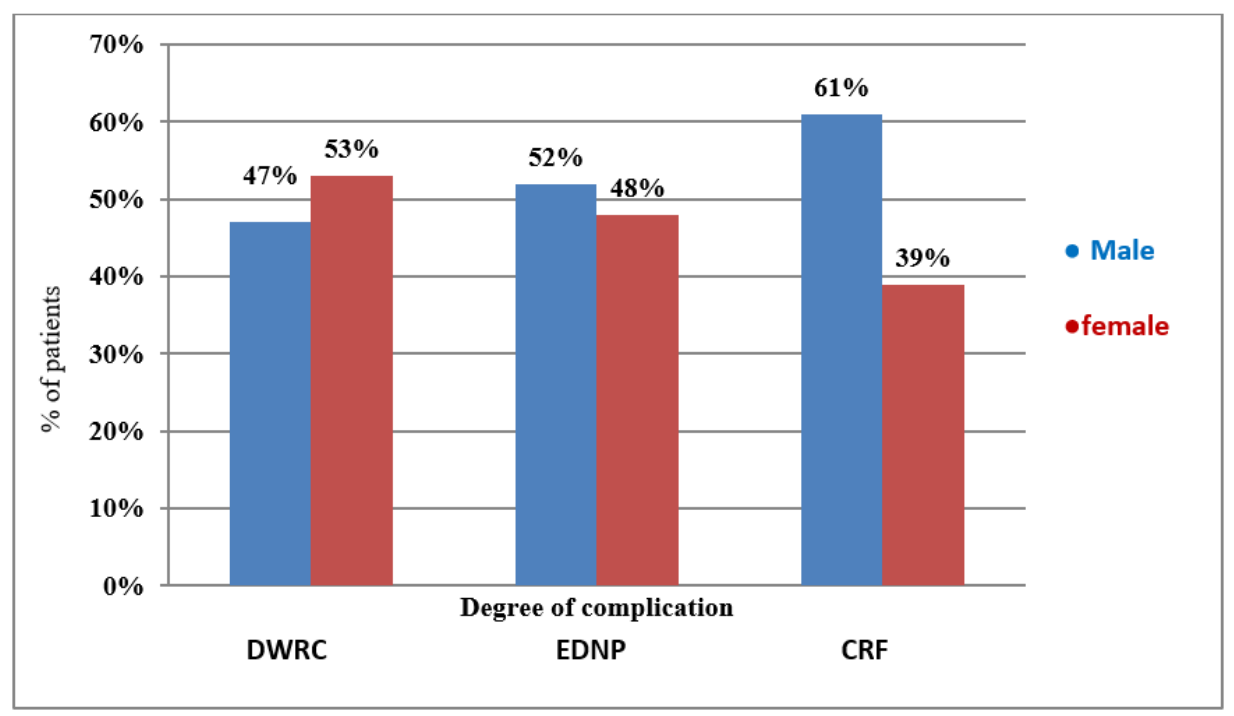

Fig. 2: Distribution of patients by degree of complication and sex.

DWRC diabetes without complications EDNP early diabetic nephropathy CRF chronic renal failure more than half of the patients $(59 \%)$ is affected by hypertension (129 cases out of 217 cases) (Figure 03).

The number of hypertensive patients is higher than the normotensive in patients suffering from an impaired kidney function. The association of arterial hypertension (hypertension) with diabetes is a classic fact; this association constitutes by its chronicity, the difficulty of its treatment and the seriousness of its complications a public health problem (Dembele et al, 2000). According to our study, the majority of our patients are hypertensive (129cases). Our data are coordinated with the study of Keller et al, which shows that $80 \%$ of patients had hypertension at the time of diagnosis of T2DM, and with the study of Bouattar et al, 2009, which found $79 \%$ of hypertensive patients with a predominance in renal insufficiency. Regarding the association of hypertension with diabetes, it appears that there is a link between hypertension and the complications of diabetes, therefore hypertension is a major factor in diabetic nephropathy.

This is confirmed by the study of Monabeka et al, 1998 which indicates that hypertension does appear to be a major factor in the development and progression of diabetic microangiopathy, in particular nephropathy.

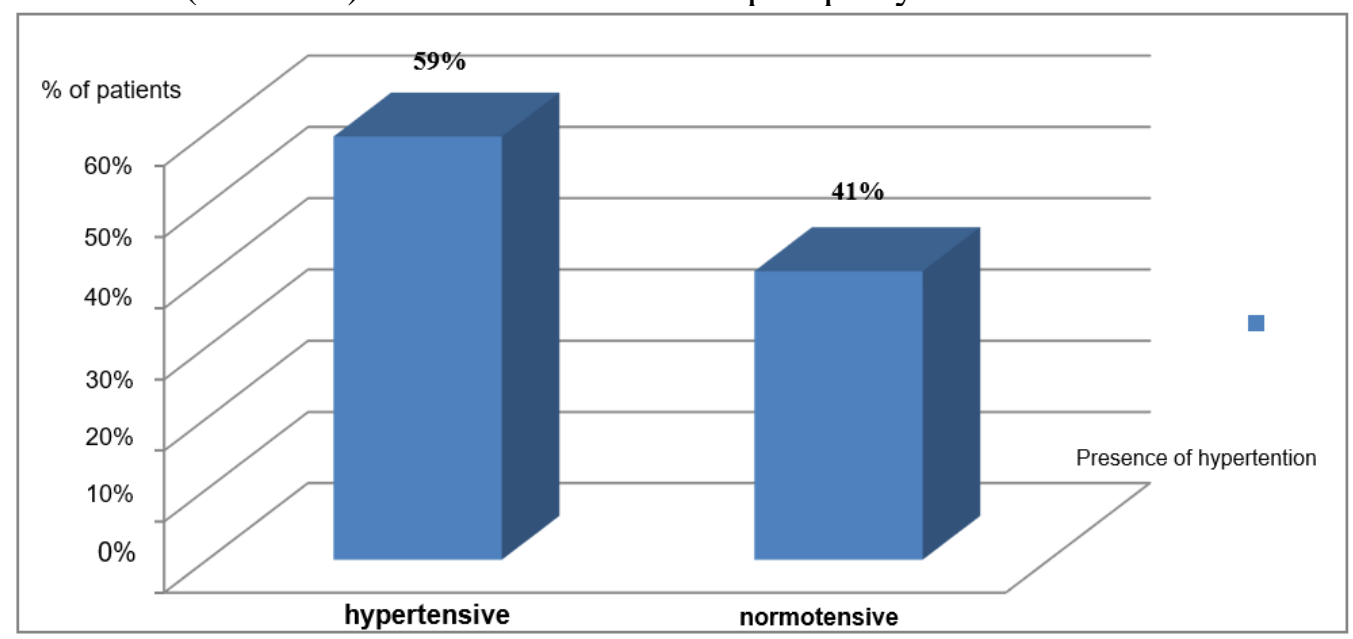

Fig. 3: Distribution of patients by hypertension. 


\section{The Biochemical Parameters:}

In this survey, unbalanced blood sugar levels were recorded in all the patients included in this study. The difference between the first group and the second is significant with a p-value of 0.037 while between the second and the third it is not $(\mathrm{p}=0.061)$. Concerning HbA1C, the difference was not significant between the group 1 and $2(p=0.063)$ or between the group 2 and $3(p=0.083)$. In the current study; a glycemic imbalance was observed in the majority of patients in all three groups, particularly in the first group of patients (DWRC) where an elevated blood sugar level was recorded. These results are confirmed by the study of (Bouattar et al, 2009) which showed that diabetes was unbalanced in $68.7 \%$ of patients, and they were recorded that $78 \%$ of diabetics without renal complications and $64.1 \%$ of renal insufficiencies patients have balance blood sugar. Interestingly, unbalanced blood sugar plays a causal role in the development of diabetes in the DN.

Optimizing blood sugar control is a fundamental aspect of the management of diabetes. There is convincing evidence that improved blood sugar control reduces the risk of microvascular complications in type 1 and type 2 diabetes (Imran \& Ross, 2008). In the study of Bouattar et al 2009; the impact of glycemic balance on the development and progression of diabetic nephropathy has been demonstrated, similarly, Weekers et al, 2003 insinuated that: "This illustrates the importance of hyperglycemia both as an initiating factor, but also as an aggravating factor, of kidney damage and should encourage all efforts to maintain optimal glycemic control even in the case of advanced DN." Blood glucose targets must be individualized; however, in most patients with type 1 or type 2 diabetes, treatment should aim for an $\mathrm{HbAlc}$ level of $\leq 7.0 \%$ to reduce the risk of microvascular complications and, in the presence of type 1 diabetes, the risk of macrovascular complications, an attempt can be made to obtain an HbAlc level $\leq$ $6.5 \%$ in certain patients with type 2 diabetes to further reduce the risk of nephropathy (Imran \& Ross, 2008), comparing with This recommendation, we notice in our study that the HbA1C level is decreasing from one group to another (DWRC, EDNP and CRF) (Table 01), this decrease is the consequence of a treatment which aims to target a rate $<7 \%$.

On the other hand, the urea level increases with the degree of renal damage. In the first group (DWRC) the urea level is always within the physiological standards, But in the second group (EDNP), there is a slight increase, and in patients with an end-stage chronic renal failure we have recorded a very high value compared to the first two groups, this increase suggests that there is an alteration in the renal function. A statistically significant increase was recorded between the group 1 and $2(\mathrm{p}=0.022)$ and also between the EDNP and the CRF group ( $\mathrm{p}$-value = $0.003)$. It is obvious that an increase in blood urea reflects a deficit in the excretion function of the kidneys (Richet, 2005). In addition, the level of urea in the blood depends on several factors and conditions, and on kidney function and protein intake. This level increases in cases of kidney failure, but the best is to dose creatinine for more specificity (Bakzinski, 2012).

Creatinine has long been the best endogenous marker of glomerular filtration. There is no doubt that it is the easiest way to estimate a patient's renal function: a single blood test gives results that can be compared to a reference value (Ythurbide and Hertig, 2012) there is a clear correlation between the creatinine level and the degree of renal complication. The creatinine level is increasing going from first to last group (Table 01), the creatinine level is always within physiological norms in DWC, and it is 
very high in the third group (CRF); a significant difference was revealed between the group 1 and 2, the same also for groups 2 and 3 with $p$ values of 0.001 and 0.000 respectively. Our results are coordinated with the study of Bouattar et al 2009, who found a level of $8.2 \pm 2.1 \mathrm{mg}$ $/ 1$ in a similar group of patients. The creatinine level is doubled in patients with EDNP, and very high in the CRF group, in agreement with Bouattar et al who identified a high level in the CRF group. The clearance of creatinine is decreased depending on the degree of renal complication. A non-significant increase was recorded between group 1 and 2 (0.056), while a highly significant decrease was found between group 2 and 3 $(\mathrm{p}=0.000)$,

We also note the existence of a negative correlation between creatinine and creatinine clearance, that is, when the ratio of creatinine increased, the rate of creatinine clearance decreased. increased creatinine levels indicate decreased glomerular filtration rate (GFR), and therefore renal failure definition (Jamal, 2015). Diabetic nephropathy is generally defined as macroalbuminuria (> $300 \mathrm{mg}$ in a 24-hr collection) or microalbuminuria and abnormal kidney function represented by an abnormality in serum creatinine, calculated creatinine clearance, or glomerular filtration rate (GFR) (Halimi, 2017). In addition, in the present study, our data (Table 01) demonstrate an increase in microalbuminuria, and it is found that patients with impaired renal function recorded a high level compared to the normal norm of microalbuminuria. Microalbuminuria is an independent marker of cardiovascular and renal risk and total mortality in $\mathrm{T} 1$ and $\mathrm{T} 2$ diabetics (Lecerf, 2000).

Concerning lipids parameters; the cholesterol level in our patients was not correlated with the degree of renal function, the TC level is very high in patients without renal complication, this level was modified in patients with ENDP and CRF, and returned to physiological standards. HDL levels are quite identical in our patients from the three groups. LDL is estimated to be elevated in the uncomplicated renal group compared to other groups and for TGs. The difference was not significant $(p=0.12$ and $p=0.23$ respectively) when compared between groups. All diabetics should benefit from screening for lipid abnormalities repeated every three or five years (depending on age) in a normal case, including a dosage of cholesterol, triglycerides and HDL cholesterol (Krolewski et al, 2001), lipid abnormalities have an impact on the progression of diabetic nephropathy (Kanoun et al, 2010). Our results for TC level are consistent with the values found by Bouattar et al, $2009(2 \pm 0.54 \mathrm{~g} / \mathrm{l})$ and by Kanoun et al, 2010) $2.22 \pm 0.54 \mathrm{~g} / 1$, our study is also confirmed by the study of (Guebre and Fouque , 2004) which shows that the total cholesterol level little modified in CRF, it is more often normal or lowered.

Several studies have shown that elevated level of triglycerides is a risk factor for diabetic nephropathy (Weekers et al, 2003) and that in all circumstances, triglycerides are a primary and independent objective (Krolewski, 2007), based on our results ( Table 01), we note that the TG level is high in patients with CRF compared to the two other groups which recorded an ideal level, our results are confirmed by the study carried out in Tunisia (Kanoun et al, 2010) which found a value of $1.95 \pm 1.02 \mathrm{~g} / 1$., On the other hand, other studies recorded a good level of TG in patients with CRF, such as the study by Bouattar et al who found a value of $1.4 \pm 0.8 \mathrm{~g} / 1$, and $1.6 \pm 0.57$ in the study of (Hannedouche, 2005). 
Table 01: Biochemical parameters in the three groups

\begin{tabular}{|l|c|c|c|}
\hline \multicolumn{1}{|c|}{ Group } & DWRC & EDNP & CRF \\
\hline Blood sugar level (g/l) & $3.17 \pm 1.3$ & $2.81 \pm 1.32$ & $2.55 \pm 1.33$ \\
\hline HbA1C (\%) & $10.74 \pm 2.26$ & $9.2 \pm 2.03$ & $8.48 \pm 1.96$ \\
\hline Urea (g/l) & $0.30 \pm 0.13$ & $0.52 \pm 0.22$ & $4.15 \pm 14.66$ \\
\hline $\begin{array}{l}\text { serum creatinine (mg/l) } \\
\text { clearance of serum } \\
\text { creatinine(ml/min) }\end{array}$ & $8.37 \pm 2.04$ & $16.56 \pm 12.81$ & $71.77 \pm 43.46$ \\
\hline $\begin{array}{l}\text { microalbuminurie } \\
\text { (mg/24h) }\end{array}$ & $59.47 \pm 33.71$ & $47.44 \pm 16.58$ & $10.75 \pm 7.98$ \\
\hline TC (g/l) & $4.27 \pm 15.58$ & $1.69 \pm 0.58$ & $2.09 \pm 1.24$ \\
\hline HDLc (g/l) & $0.4 \pm 0.14$ & $0.38 \pm 0.16$ & $0.39 \pm 0.12$ \\
\hline LDLc(g/l) & $25.09 \pm 156.31$ & $0.97 \pm 0.45$ & $0.99 \pm 0.65$ \\
\hline TGs(g/l) & $1.09 \pm 0.77$ & $1.30 \pm 0.64$ & $1.72 \pm 0.91$ \\
\hline
\end{tabular}

\section{Ionic Balance:}

In this study, the average ion balance level (sodium, potassium, chlorine) is variable but remains within physiological norms in most patients in the 3 groups studied (Table 2). For patients who have developed EDNP or CRF, they have mild hyponatremia. We also observed a slight increase in the mean serum potassium level in patients with CRF. This result is confirmed by the study of (Azzedine, 2011), who also found a slight increase in serum potassium levels in patients with CRF. It is admitted that the potassium balance is balanced up to the late stage of chronic kidney failure, this phenomenon is due to the deficit in renal excretion of potassium, beyond the mechanisms of adaptation. Thus, many experimental arguments indicate that hyperkalemia is the most formidable complication of blocker treatments Reninangiotensin system, which encourages increased vigilance in the use of nephropotectors and adequate dietary and therapeutic measure.

Table 02: ionic parameters in the three groups

\begin{tabular}{|c|c|c|c|}
\hline Group & DWRC & EDNP & CRF \\
\hline Sodium (mmol/l) & $134.46 \pm 6$ & $127 \pm 30.09$ & $128.92 \pm 23.93$ \\
\hline Potassium (mmol/l) & $4.06 \pm 0.85$ & $4.42 \pm 1.53$ & $4.71 \pm 1.05$ \\
\hline Chlorine (mmol/l) & $90.21 \pm 27.9$ & $98 \pm 6.51$ & $102 \pm 7.89$ \\
\hline
\end{tabular}

\section{CONCLUSION}

According to this study, Creatinine was found to be the simplest way to estimate the function and the degree of a renal complication. The clearance of creatinine is an essential way to better knows the evolutionary stage of DN. In all of our diabetic patients, an unbalanced blood sugar level is recorded, so it is considered a real risk factor for the development of diabetes towards diabetic nephropathy and an end-stage chronic kidney failure. Microalbuminuria is a sign of a diabetic kidney disease that should be actively sought in any diabetic patient, and in our patients with a renal alteration, it is noted that the level of microalbuminuria exceeds physiological standards. 59\% of our study population are affected by high blood pressure, which appears as a major factor in the development and the progression of diabetic nephropathy, thus urea and triglycerides are also biological markers and indicators of the severity of kidney damage.

Acknowledgments: The volunteers who participated in the study are gratefully thanked. Also, we would like to thank Sidi-bel-Abbes University Hospital and the staff of Guambeta Diabetes Home for 
all their support in performing the needed analysis.

Conflict Of Interest: The authors have no conflicts of interest.

\section{REFERENCES}

Ali Imran, S; \& Ross S.A (2008) Objectifs du contrôle de la glycémie. Lignes directrices de pratique clinique 2008 de l'Association canadienne du diabète pour la prévention et le traitement du diabète au Canada. Canadian Journal of Diabetes, 32(1), S3134.

Azzedine, R.S (2011) Etude de quelques paramètres biologiques et physiologiques de la Néphropathie Diabétique. Mémoire en vue de l'obtention du diplôme : Magister en Biologie et Physiopathologie Cellulaire. Université Mentouri Constantine. Algérie.

Bakzinski, A Urée (2012). http://www.commentguerir.com/a rticle/uree.

Blickle, J. F; Attali, J.R.; Barrou, Z.; Brocker, P; De Rekeneire, N; Verny, C (1999) Le diabète de sujet Agé. Diabetes \& Métabolism (Paris), 25(1). 84-93

Bouattar,T; Ahid, S; Benasila, S; Mattous, M; Rhou, H; Ouzeddoun, N (2001) Les facteurs de progression de la néphropathie Diabétique: prise en charge et évolution. Néphrologie and Thérapeutique, 5, 181-187.

d'Ythurbide, D and Hertig, A(2012) Augmentation de la créatinine. Médecine Générale, 26 (876), 152-153.

Dembele, M ; Sidibe, A.T; Traore,H.A; Tchombou Hic; Zounet, B; Traore A.K (2000) Association HTAdiabete sucre dans le service de medecine interne de l'hopital du point G-Bamako. Médecine d'Afrique Noire, 47 (6), 277- 280.

Djrolo, F; Vénérand, G.A; Dossou, G.A;
Fabien, H; Simon, A; Benjamin (2001) Néphropathie diabétique : une étude épidémiologique fondé sur la protéinurie dans une population de diabétiques noirs africains à Cotonou, Bénin. Cahier d'étude et de recherche francophones / Santé, 11 (2) : 105-109.

Fédération International du Diabète (FID) (2013) Atlas du diabète de la FID (6ème édition). http://www. diabetesatlas.org/. Pp 22-26.

Fédération International du Diabète (FID) (2018) Atlas du diabète de la FID (3ème édition). http://www. diabetesatlas.org/.

Fontbonne A (2014) Epidémiologie des états diabétiques. In L. Monnier (Ed.), Diabétologie (2ème édition) (pp. 3-8). Paris. Elsevier Masson.

Guebre E.F; \& Fonque D (2004) Altérations métaboliques au cours de l'insuffisance rénale chronique. Nutrition Clinique et Métabolisme, 18(1), 3-6.

Halimi, J.M.; Hadjaji, S; Allaert F.A; Artigou, J.Y; Beaufils, M. (2007) Microalbuminurie et excrétion urinaire d'albumine. Recommandations pour la pratique clinique. Néphrologie et Thérapeutique, 3(6), 384-391.

Hannedouche T; Krummel T; Parvez B.P (2005) Néphroprotection, comment ralentir l'évolution de l'insuffisance rénale chronique?. Néphrologie et thérapeutique, 1.135-144.

Jamal, A (2015) Gestion de la néphropathie ddiabétique : progrès récents et perspectives d'avenir. Syndrome métabolique et diabète de: Recherche et études cliniques, 9 (4). 343-358.

Kanoun, F; Ben Alaya, N; Idriss, S; Sayem, N; Chihaoui, M; Harzallah, F; (2010) Appréciation du profil tensionnel par la mesure ambulatoire de la pression 
artérielle chez les diabétiques hypertendus traités : La Tunisie Médicale, 88(12) : 885-889.

Krolewski, A. S; Canani D. P.K. NG LH Warram, J. (2001) Génétique de la néphropathie diabétique : ou en sommes-nous dans la recherche des génes de suceptibilité ? (2001). http://www.sfndt.org/sn/ PDF/enephro/publications/ actualites/2001/2001_23.pdf.

Lecerf, J.M (2000) Lipides et diabète : comprendre, interpréter et traiter une dyslipidémie chez un diabétique Approche clinique et thérapeutique. Act. Méd. Int. Métabolismes - Hormones Nutrition, IV (2), 69-77.

Malek, R., Belateche, F., Laouamri, S., Hamdi-Cherif, M., Touabti, A., Bendib, W (2001) Prévalence du diabète de type 2 et de l'intolérance au glucose dans la région du Sétif (Algérie). Diabetes Metabolism (Paris), 27(2). 164-171.

Masakazu, H; Kazunori, U; Daisuke, K; Tetsuya. B Tatsumi, M., Hirofumi, M (2015) Une nouvelle classification de la néphropathie diabétique: un rapport du Comité mixte sur la néphropathie diabétique. Journal of Diabetes Investigation, 6 (2): 242-246.

McIsaac, R and Jerums, G (2003) Gestion de la néphropathie diabétique. Diabetes voice, 48, 15-18.

Monabeka, H.G; Bouenizabila, E; Mbadinga, M; Kibangou, N; Etitiele, F (1998) Hypertension arterielle et diabete sucre à propos de 152 diabetiques hypertendus. Médecine d'Afrique Noire, 45 (2), 106-109.

Odile, K.J. ; Alain, W. ; Philippe, R; and Hubert, A (2008) Diabète traité en France: un taux de prévalence proche de $4 \%$ et des disparités géographiques croissantes.
Bulletin Epidémiologique Hebdomadaire (BEH), (43), 409413.

Organisation mondiale de la santé (OMS) (2018) Diabète. Aide-mémoire N 312.

http://www.who.int/mediacentre/f actsheets/fs312/fr/.

Perucca, J; Bouby, N; Valeix, P; Jungers, P; Bankir (2008) Différence de concentration urinaire selon le sexe ou l'origine ethnique: implications possible dans la susceptibilité variable à différentes pathologies rénales et cardiovasculaires: Néphrologie et Thérapeutique, 4, 160-172.

Philip, M ; Richard, E. G; Lori, M; Peter, $S$ (2013) La néphropathie chronique en présence de diabète. Canadian Journal of Diabetes, 37(suppl 5), S504-S512.

Richet, G (2005) Introduction du dosage de l'urée sanguine en pathologie rénale. Néphrologie et thérapeutique, 1, 265- 268.

Valérie, J et Philippe K (2010) La néphropathie diabétique une sucrée de complication. Le Médecin du Québec, 45(9), 4955.

Weekers, L; Krzesinski, JM. (2005) La néphropathie diabétique. Revue Medicale de Liege, 60(5-6), 479486.

Weekers, L; Scheen, A.J; \& Rorive, G (2003) Prévention de la Néphropathie Diabétique: de la microalbuminurie à l'insuffisance rénale terminale. Revue Medicale de Liege, 58 (5), 297-306.

Zaoui, S; Biémont, C; and Meguenni, K (2007) Approche épidémiologique du diabète en milieux urbain et rural dans la région de Tlemcen (Ouest algérien) (2014) Cahiers Santé, 17(1), 15-21. 